\title{
Technology needs assessment for climate change adaptation: Experiences of Mauritius and Seychelles
}

\author{
Deenapanray, Prakash N. K.; Trærup, Sara
}

Published in:

Regional Environmental Change

Link to article, DOI:

10.1007/s10113-021-01859-y

Publication date:

2021

Document Version

Publisher's PDF, also known as Version of record

Link back to DTU Orbit

Citation (APA):

Deenapanray, P. N. K., \& Trærup, S. (2021). Technology needs assessment for climate change adaptation: Experiences of Mauritius and Seychelles. Regional Environmental Change, 22, [2]. https://doi.org/10.1007/s10113-021-01859-y

\section{General rights}

Copyright and moral rights for the publications made accessible in the public portal are retained by the authors and/or other copyright owners and it is a condition of accessing publications that users recognise and abide by the legal requirements associated with these rights.

- Users may download and print one copy of any publication from the public portal for the purpose of private study or research.

- You may not further distribute the material or use it for any profit-making activity or commercial gain

- You may freely distribute the URL identifying the publication in the public portal 


\title{
Technology needs assessment for climate change adaptation: Experiences of Mauritius and Seychelles
}

\author{
Prakash N. K. Deenapanray ${ }^{1,2} \cdot$ Sara Trærup ${ }^{3}$ \\ Received: 19 March 2021 / Accepted: 16 November 2021 \\ (c) The Author(s), under exclusive licence to Springer-Verlag GmbH Germany, part of Springer Nature 2021
}

\begin{abstract}
Besides access to climate finance and capacity building, developing countries, comprised mainly of least developed countries (LDCs) and small island developing states (SIDS) have negotiated for increased technology transfer to support their climate change adaptation. The Global Environment Facility has been supporting LDCs and SIDS to develop technology needs assessments (TNAs) to leverage international climate finance, and 62 countries have conducted a TNA to date. Ten SIDS are currently completing their TNAs, and 9 more will start the process in 2021 . The focus of this paper is on in-country processes that have not received much attention to date. We find that an efficient TNA process is characterized by the adoption of an inclusive multi-stakeholder process, using existing institutional structures to increase ownership, and applying a learning-by-doing approach. An effective TNA process supports the formulation of national climate change policies and strategies and importantly enables the country to leverage international climate finance. For the latter, an effective TNA should address more closely the investment criteria of the Green Climate Fund. The lessons learned are shared to better inform forthcoming TNA processes in SIDS.
\end{abstract}

Keywords Technology needs assessment $\cdot$ Climate change adaptation $\cdot$ Small island developing States $\cdot$ Lessons learned

\section{Introduction}

Technology, although not a panacea, is an essential element for reducing vulnerabilities or enhancing resilience in the face of a changing climate (Biagini et al. 2014; Ockwell and Byrne 2016; Kuhl 2020). In its broadest sense, technology has been defined as composed of hardware, knowledge (or software), and organizational (or orgware) components that are interrelated (Brooks 1995; Boldt et al. 2012). The

Communicated by Tony Weir

Prakash N. K. Deenapanray

sanju@ecolivinginaction.com

Sara Trærup

slmt@dtu.dk

1 Faculty of Sustainable Development and Engineering, Université Des Mascareignes, Rue de la Concorde, Roches Brunes, Rose Hill, Mauritius

2 ELIA-Ecological Living In Action Ltd, 74 Société La Flèche, La Gaulette 91104, Mauritius

3 UNEP DTU Partnership, Technical University of Denmark, Marmorvej 51, 2100 Copenhagen, Denmark tangible aspects, such as equipment and products constitute the hardware element; the know-how, experiences and practices form the software element associated with the production and use of the hardware; and the organizational framework required to operationalize these two elements is referred to as orgware. The introduction of a new or relatively unfamiliar technological concept or practice in the recipient country is understood as technology transfer (Brooks 1995; Bozeman 2000; Boldt et al. 2012).

The need for the transfer of environmentally sound technologies to support the sustainable development of developing countries was formulated as early as 1992 at the UN Conference on Environment and Development (UNSD 1992), and specifically for climate change (adaptation and mitigation) under the United Nations Framework Convention on Climate Change (UNFCCC 1992). Article 4(5) of the UNFCCC specifically refers to the transfer of climate technologies from developed to developing countries supported by adequate access, financing, and capacity building (UNFCCC 1992). Commitments to promote technology transfers to developing countries have been renewed at every Conference of Parties (COP) to the UNFCCC. The Technology Transfer Framework (TTF) formed part of the 
Marrakech Accords that emanated from COP7 (UNFCCC 2001). The TTF consists of five thematic functions, and the Technology Mechanism (fifth thematic function of the TTF), comprised of the Technology Executive Committee (TEC) as policy arm and the Climate Technology Center and Network (CTCN) as operational arm, was established in 2010 under the Cancun Agreements at COP16 (UNFCCC 2010) to facilitate enhanced action on climate technology development and transfer.

The Paris Agreement (UNFCCC 2015) highlighted the importance of technology in implementing both mitigation and adaptation actions. The Technology Mechanism is expected to facilitate and promote enhanced action on technology to help countries achieve the goals of the Paris Agreement, while at the same time recognizing the importance of rapidly accelerating transformational changes toward climate resilience and reduced greenhouse gas emissions (Haselip et al. 2019). In December 2018, the Parties at COP24 completed the drawing up of a new Technology Framework to guide the Technology Mechanism (UNFCCC 2018). The Technology Framework placed increased emphasis on technology needs assessments (first thematic of the TTF) and their central role in promoting and facilitating enhanced actions on technology development and transfer.

Technology transfer is obviously sequential to technology research and development, and the technology development and transfer cycle are illustrated in Fig. 1. This figure highlights the essential fact that the transfer and adoption of any climate technology have to be anchored into the needs of the recipient country based on its specific vulnerabilities and adaptation priorities. In order to support developing countries define their technological needs for climate adaptation (and also mitigation), the Global Environment Facility (GEF) has been providing financial assistance to countries under the UNFCCC Poznan Strategic Programme on Technology Transfer. The assessment of technology needs is situated along with the technology transfer and adoption cycle as shown in Fig. 1, and the process comprises three interrelated steps, namely: (i) technology identification and prioritization; (ii) analysis of barriers and enabling environment for prioritized technologies; (ii) formulation of technology action plans (TAPs) (Haselip et al. 2019). The TNA project provides a robust methodology for assessing climate technology needs from identifying and prioritizing technologies in priority areas to identifying the barriers to technology transfer to establishing the enabling environment required for technology transfer to take place. For adaptation technologies, the prioritization of technologies rests on a priori vulnerability assessments being carried out to identify the priority sectors of interventions. The post-Poznan TNA process synthesises all analyses in the TAP that provides a roadmap for the technology transfer and adoption cycle (UNFCCC 2008). Also, the pre-Poznan TNAs adopted a range of adaptation typologies, including a narrow definition of climate technologies consisting predominantly of hardware, which on their own (i.e., without the software and orgware elements) may not necessarily reduce climate vulnerabilities and be effective in sustainable development (Fida 2011; Trærup and Christiansen 2015).

To date, two phases ( 24 countries in phase 1 and 26 countries in phase 2) of the TNA projects have been completed, while a third phase ( 22 countries) is under completion. Phase four of the global TNA project has been approved and it will cover African countries (Ethiopia, Guinea-Bissau, Lesotho, Somalia, South Sudan, and Yemen) and small island developing states (Comoros, Kiribati, Maldives, Niue, Papua New Guinea, Solomon Islands, Timor-Leste, Tonga, Tuvalu, Bahamas, and St. Kitts and Nevis). The literature is well endowed with studies investigating the development (Bozeman 2000), adoption (Eichberger and Guerdjikova 2012; Zilberman et al. 2012) and diffusion (Biagini et al. 2014) of climate adaptation technologies. In contrast, and despite supporting 89 countries across four phases, there is a conspicuous lack of information on the in-country experiences
Fig. 1 Technology needs assessment within the technology transfer and adoption cycle

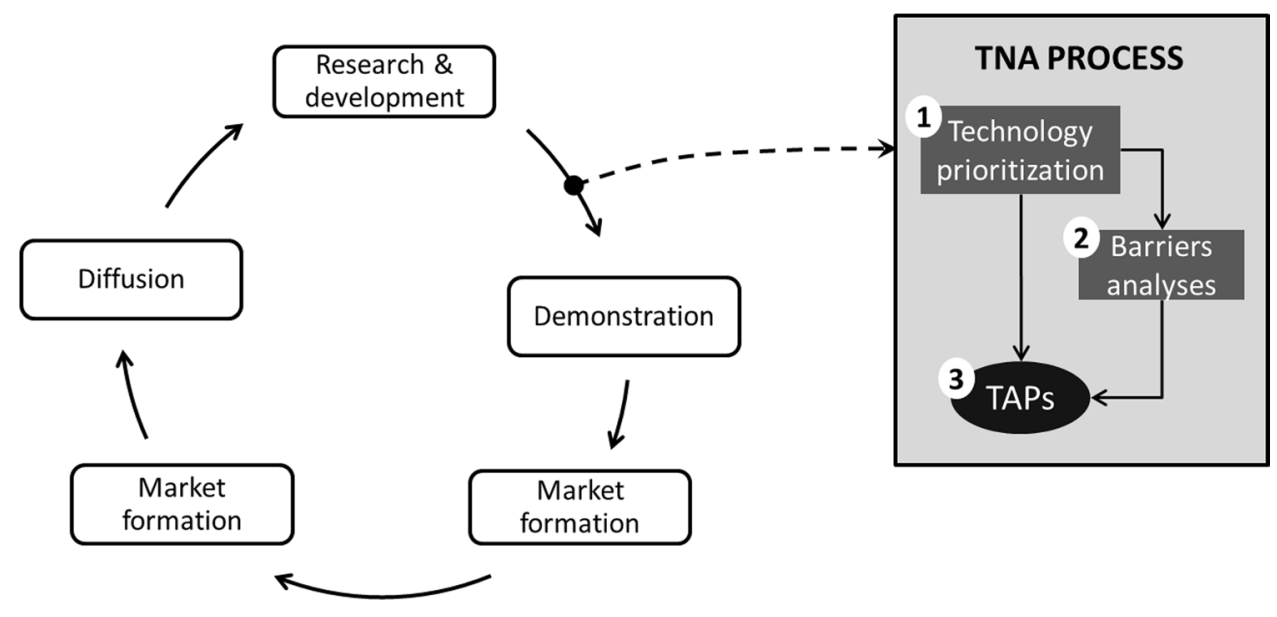


on conducting the assessment of climate technology needs. Also, while the TNA process is subtended by a robust methodology, the quality of outcomes relies on the efficiency and effectiveness of these in-country processes.

The paper attempts to address this research gap through two research questions:

1. What are the enablers of an efficient TNA process? and

2. How can the effectiveness of the TNA process be characterized?

Discussions revolve around the lessons learned in two African SIDS-i.e., Mauritius and Seychelles-that participated in phase 1 and phase 2, respectively, of the global TNA project. We are confident that these lessons will be relevant to the African countries and SIDS that will participate in Phase 4 of the global TNA project.

\section{Methodology}

This section provides the approach used to address the two research questions that constitute the focus of the paper. The justification for the proposed approach framed in Fig. 2 is provided from three perspectives: (i) problems inherent to the TNA process; (ii) the contested positions of what would constitute an effective TNA process under the UNF$\mathrm{CCC}$; (iii) recommendations of the independent evaluation of phase 1 and phase 2 TNA processes. The first research question is analyzed from four interrelated enablers (stakeholder engagements, institutional arrangements, replication of methodology, and capacity-strengthening) that make the TNA process efficient. Efficiency here is assessed in terms of the enablers that optimize the inputs of resources, such as stakeholders' time and knowledge in order to complete the
TNA project in a period of around 2 years. When designed and applied successfully, these enablers can translate into an effective TNA process. Effectiveness reflects the quality of the TNA process in achieving desired objectives that are framed in terms of (i) supporting the formulation of national policies and strategies for reducing climate vulnerabilities and/or increasing climate resilience, and (ii) bankability of TAPs for attracting international climate finance. The discussions of in-country experiences and lessons learned from Mauritius and Seychelles are supported by unique vantage points of the authors in the TNA project (PNKD was the Team Leader for the TNA projects in Mauritius and Seychelles; ST is the Manager of the global TNA project). The focus is on adaptation technologies since SIDS is known to be particularly vulnerable to impacts of climate change (IPCC 2014).

\section{Problematizing the technology needs assessment process}

There are several the features of TNA process, which if not addressed properly, may limit its implementation and institutionalization. These features, as observed by the authors, are:

- Step 1 of the TNA requires a priori identification of vulnerable sectors through vulnerability and climate risk assessments. Hence, the quality of the TNA rests largely on the quality of these assessments;

- The three steps of the TNA process are usually visualized sequentially (Bold et al. 2012). This may give the impression that it is sufficient to proceed from one step to the other without understanding the entire process upfront. Such a linear approach may significantly affect the quality of TAPs. A better representation of the interlinkages between the three TNA steps is illustrated in Fig. 2;
Fig. 2 Framework for assessing lessons learned from in-country TNA experiences

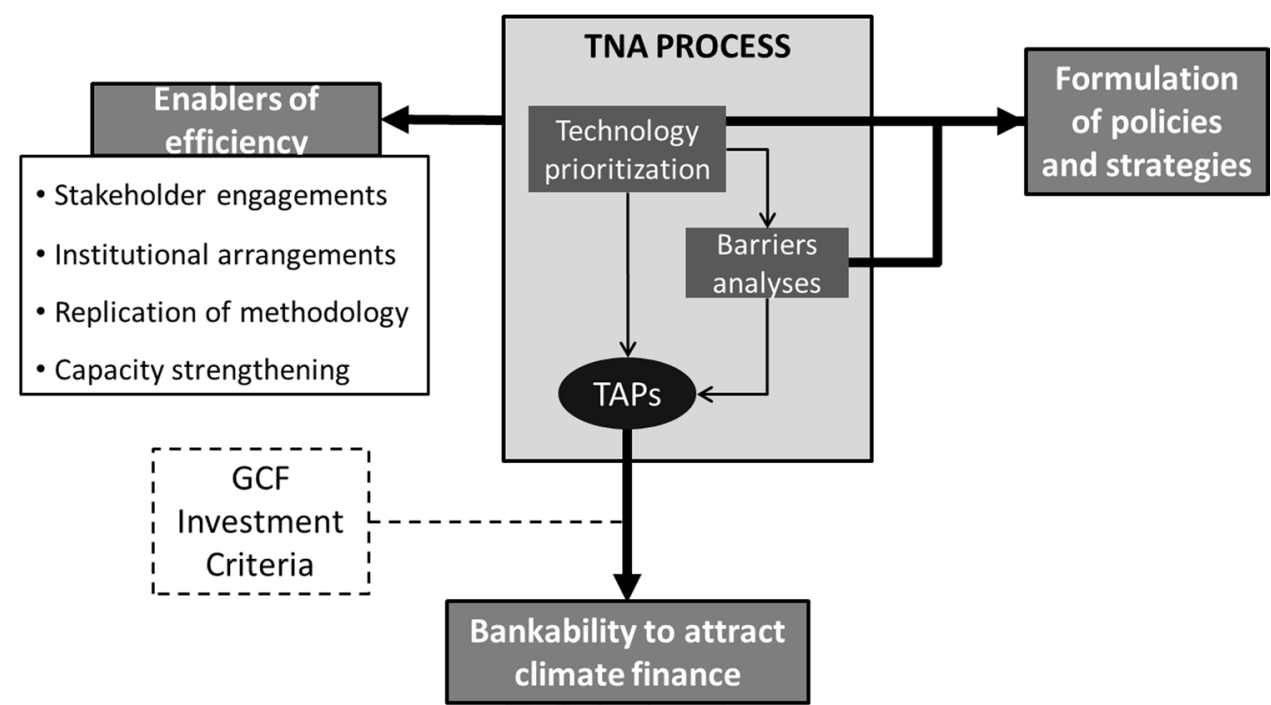


- Countries typically receive a GEF grant between USD120,000 to USD150,000 to complete a TNA. The limited financial resources limit the sectoral scope of the TNA. This relatively small budget does not position the TNA project favorably in terms of time commitment within the larger portfolio of projects in the public institution or ministry managing the TNA;

- The process is heavily dependent on national consultants thereby constraining the scope for institutional strengthening and updating existing TAPs; and

- Limited human capacity building is provided on the TNA process and tools that can compromise the quality of TAPs, and hence bankable technology transfer projects for adaptation.

\section{Contested views of a successful technology needs assessment process}

An important question relates to determining what would constitute a successful TNA. There is no normative framework to reply to this question. A detailed discussion of the different positions taken in climate negotiations by developed and developing countries on this issue has been provided by Oh (2019). The developed country view has been on the integration of the results of TNA into national development strategies and goals. In contrast, developing countries have argued an effective TNA process to culminate in bankable TAPs for leveraging international climate finance to support technology transfer. While the prerogative for developing countries is to use the results of TNA to attract climate finance, an agreement was reached by Parties during the COP18 in 2012 for integrating the TNA process with other UNFCCC initiatives, including nationally appropriate mitigation actions (NAMAs), national adaptation plans (NAPs), and low-emission development strategies (LEDS) (UNFCCC, 2012). More recently, around 106 non-annex I parties have made implementation of their NDCs conditional upon the development and transfer of technologies (Charlery and Traerup 2019). Without going into the merits or otherwise of these diverging views, the synthetic approach used here is to assess the effectiveness of the TNA process from both perspectives.

\section{Evaluation of the global technology needs assessment project}

An independent evaluation of the first two phases of the global TNA project has made several recommendations related to knowledge management of in-country processes and their capture and dissemination among countries carrying out TNAs. In particular, several improvements have been proposed to increase the effectiveness of TNAs-TAPs (UNEP 2020):
- Increasing linkages between countries to enhance opportunities for sharing lessons learned;

- To place more emphasis on national processes. The evaluations noted that many of the factors for greater national value were in the control of implementing countries. At the project level, they include integration of such work within national decision making and climate change structures, energetic leadership at an appropriate national level with access to senior officials and to a wide range of ministries and departments, and a reasonable provision for national resources to complement the external finance;

- Follow-ups at the national level after the TNA project had ended was critical for the use of TAPs in national planning, financing, and programming;

- Ensuring country self-sufficiency in terms of capacities in implementing the TNA cycle, including processes, methodologies, and tools beyond the TNA project; and

- Ensuring adequate participation of the private sector.

The evaluation concluded that there have been few attempts to date to investigate national TNA processes and to share lessons learned between countries. The discussions of lessons learned in Mauritius and Seychelles using the framing shown in Fig. 2 squarely address this research gap.

\section{Technology needs assessment outcomes in Mauritius and Seychelles}

Before addressing the two research questions in terms of the efficiency and effectiveness of TNAs, the outcomes of the TNA processes in Mauritius and Seychelles are briefly discussed by looking at the sectoral scope and prioritized climate adaptation technologies. Tables 1 and 2 summarize the priority adaptation sectors and the prioritized adaptation technologies emanating from the TNA processes in Mauritius (Republic of Mauritius 2013) and Seychelles (Government of Seychelles 2018), respectively.

The priority adaptation sectors in Mauritius and Seychelles, namely agriculture, water, and coastal zones are well aligned with the three main adaptation sectors in the overall country portfolio in Phases 1 and 2 of the global TNA project as discussed above. An inherent characteristic of islands is their relatively high ratio of coastal perimeter to the land surface area, resulting in higher exposure and vulnerability of coastal areas to the impacts of climate change (De Commarmond and Payet 2010). The agriculture-water nexus is also high, making the two sectors of the highest adaptation priority. In Mauritius, close to $50 \%$ of all water is abstracted and used in agriculture (Deenapanray and Ramma 2015). In Seychelles, the availability of productive land for agriculture is highly constrained by the granitic topography 
Table 1 Priority adaptation sectors and prioritized adaptation technologies-Mauritius

\begin{tabular}{|c|c|}
\hline Technology & Technology description \\
\hline \multicolumn{2}{|l|}{ Agriculture } \\
\hline Integrated pest management (IPM) & $\begin{array}{l}\text { An approach that integrates a range of practices for economic control of pests. It aims to suppress pest } \\
\text { populations below the economic injury level. Four practices are covered: (i) pruning of fruit trees and } \\
\text { use of bird net, (ii) inoculative release of predators to control the population of Tetranycus urticae, (iii) } \\
\text { release of parasitoids (Encarsia Formosa and Eretmocerus eremicus), and (iv) field sanitation using field } \\
\text { cages (augmentorium), protein bait and MAT block. The target is to use scale-up IPM to cover } 1200 \text { ha } \\
\text { under food crop cultivation over } 10 \text { years, involving about } 2400 \text { small-scale growers }\end{array}$ \\
\hline Micro irrigation & $\begin{array}{l}\text { Consists of a combination of low-head, low-cost gravity-fed drip irrigation kits, micro sprinklers, and } \\
\text { micro-tube drip systems suited for smallholder farmers. It delivers water precisely and efficiently and is } \\
\text { useful in addressing the growing competition for scarce water resources. Target is to cover } 250 \text { ha under } \\
\text { food crop production over } 5 \text { years, thereby benefiting } 500 \text { small-scale planters including female farmers } \\
\text { suffering from frequent crop failure and yield loss due to water shortage }\end{array}$ \\
\hline
\end{tabular}

Water

Desalination

Roof top rainwater harvesting

Hydrological model

Coastal zones

Dune and vegetation restoration

Wetland protection

Rock revetment
A typical plant uses reverse osmosis desalination to increase water supply by $300 \mathrm{~m}^{3} /$ day. It uses either seawater of salinity level greater than $10,000 \mathrm{ppm}$ or brackish water with salinity levels varying between 1000 and $10,000 \mathrm{ppm}$. The target is to get at least half of the 120 hotels situated in the coastal zone to adopt the technology over a 10 -year period at a rate of 5 plants per year starting with those found in the most water-deficient regions

This technology is aimed at households, and it consists of a collection, the connecting pipe with an outflow for discharge if settleable solid particles, water tank $(500 \mathrm{~L})$, and overflow with drainage facilities in the form of absorption pits to promote groundwater recharge. A total of 25,000 housing units are targeted each year over a 10-year period, starting in locations receiving an annual rainfall greater than $1500 \mathrm{~mm}$ per year. This will allow increased levels of piped water supply to regions receiving less precipitation

Hydrologic models are used for understanding hydrologic processes. The action plan consists of putting in place a telemetry system for high-quality data acquisition, procurement of off-the-shelf hydrological modeling software and logistics (stochastic or process-based), and institutional and human capacity building over a period of 5 years

Coastal dunes act as a buffer against extreme weather events such as extreme tides and storm surges. Healthy dunes are vegetated by native plant species that are effective at holding onto the sand because of their dense root system. They can therefore reduce the rate of dune erosion. The succession of creepers and shrubs also filter and regulate runoff during rainstorms. The target is public beaches (5-year period) where adequate setback exists making it possible to restore the seaward face of dunes

Wetland protection is for re-establishing ecosystems functions, such as filtration of water and buffering during flooding from intense precipitation for the benefits of coastal communities and infrastructure. The target group implementing this technology would be private properties that hold wetlands and/or are in a buffer area of $30 \mathrm{~m}$ from wetlands. These would be purchased for restoration over 5 years

Revetments are hard-engineered structures used to prevent erosion along the shoreline. They are typically built of rocks, concrete, or other structural materials, and are sloped facing the sea with the aim of dissipating wave energy. Coastal regions suffering from acute coastal erosion are the target sites for applying the technology of the three main inhabited islands. The topography also constitutes a significant limitation to scaling up the conventional ways of capturing and storing water in dams. Despite the fact that agriculture was not retained as a priority sector in Seychelles, the agriculture-water nexus is still revealed through the ground surface rainwater harvesting technology that is expected to increase water availability for agricultural production.

The prioritized adaptation technologies are also well aligned with the portfolio of technologies identified across countries participating in TNA phase 1 and phase 2 countries (Trærup and Christiansen 2015; Le Manceau et al. 2020). It is noteworthy that prioritized coastal zone adaptation technologies consisted of a combination of soft (ecosystem-based) and hard technologies with the former being more prominent in both islands. Nature-based technology is also used in integrated pest management (Mauritius). There is also the prominence of software such as coastal risk mapping and monitoring (Seychelles) and hydrological modeling (Mauritius) as adaptation technologies. In both countries, orgware cuts across all technologies. It is reflected in the institutional structure and organizational coordination that enable their implementation, and monitoring and evaluation. 
Table 2 Priority adaptation sectors and prioritized adaptation technologies-Seychelles

Technology Technology description

Water

Rooftop rain water harvesting with water treatment The technology is as described in Table 1. The TAP is based on encouraging each houseand safe storage hold to have rainwater harvesting $(\mathrm{RWH})$ system with appropriate water treatment and water storage. Only $4.5 \%$ of households are equipped with RWH systems. Twenty-five thousand $(25,000)$ households are targeted over a period of 5 years corresponding to $90 \%$ of total households nationwide

Water efficient appliances

The residential sector is the highest end-use sector in Seychelles. Residential water conservation efforts can make a positive contribution to reducing pressure on water resources. The most common water-efficient fixtures and appliances include double-flush toilets, showerheads, and washing machines. The comprehensive replacement of household appliances (showers, toilets, and dishwashers) with highly efficient devices can potentially reduce indoor water consumption by 35 to $50 \%$. The TAP targets 25,000 households over a period of 5 years corresponding to $90 \%$ of total households nationwide

Ground surface rainwater harvesting

Coastal zones

Coastal risk mapping and monitoring

Coastal ecosystem restoration: wetlands and dunes
The technology with the most potential in Seychelles is small reservoirs with earthen bunds or embankments (gabions) to contain runoff or river flow strengthened with gabions. This technology can help the agricultural sector to have a constant and regular water supply for agricultural production thereby minimizing the impact of climate change on crop and livestock production. The TAP identifies fifty (50) sites on Mahe, Praslin, and La Digue, and implementation is expected over a 10 -year period

This technology encompasses a variety of methods to map and monitor coastal areas and coastal dynamics, both onshore and offshore to just beyond the coral reefs. The geographic focus is on the main three islands (Mahé, Praslin, and La Digue) at vulnerable sites where critical infrastructure is located and/or further development planned, and sustained at least until 2030. The technology includes: (i) mapping of coastal ecosystems using high-resolution satellite imagery and ground-proofing, bathymetry; (ii) creating risk maps identifying key coastal areas susceptible to heavy rains, flooding, erosion, and other climate impacts; (iii) beach profiling in key vulnerable sites; (iv) studies of coastal dynamics (waves, currents, and sand movement) at vulnerable sites using acoustic doppler current profilers installed offshore near vulnerable beaches; (v) modeling impacts of coastal protection measures or developments on an existing coast

Although the degree of severity of coastal erosion and flooding may at times call for fastacting hard engineering solutions, in many cases these challenges can be dealt with by planning ahead and using natural, ecosystem-based adaptation (EBA) methods for the long-term adaptation results. EBA approaches have many benefits: they are conducive to community involvement, they create and maintain habitat for wildlife, they provide a space for social and leisure activities, and they tend to be more esthetically pleasing than hard engineering approaches. The TAP identifies vulnerable sites as follows for the application of EBA approaches that can be mixed with engineered solutions: (i) dunes-2 vulnerable sites on Mahé (Baie Lazare and Beau Vallon) and two sites on Praslin (Cote D'Or and Grand Anse); (ii) wetlands—9 vulnerable sites on Praslin (Baie Ste Anne village, Grand Anse Village, Anse Kerlan, Nouvelles Decouvertes, Anse St. Saveur - Anse Takamaka, Au Cap Wetlands, Anse Gouvernement, Cap Samy, and Cote D'or). The timeline is 2030

\section{Efficiency of the technology needs assessment process}

\section{Inclusive multi-stakeholder process as a key enabler}

Figure 3 illustrates the steps in carrying out the TNA project and the timelines for Mauritius and Seychelles. There are several points to note so as to better contextualize how critical adequate stakeholder engagement and coordination is to the successful implementation of the TNA project. First, and notwithstanding the fact that there were administrative delays (in the recruitment of consultants) to start project implementation in Mauritius and Seychelles, the implementation time was relatively long, ranging between 2 and $2 \frac{1}{2}$ years. Stakeholder engagement is a requisite in each of the three steps in the TNA process (Haselip et al. 2019), and well-designed multi-stakeholder processes are known to be vital for achieving sustainable development objectives (Hemmati 2002; Fowler and Biekart 2017). The efficiency of the TNA process is directly related to the active participation of stakeholders in terms of both their availability and willingness to contribute. Some of these stakeholders participate 
MAURITIUS

Start: Feb 2011

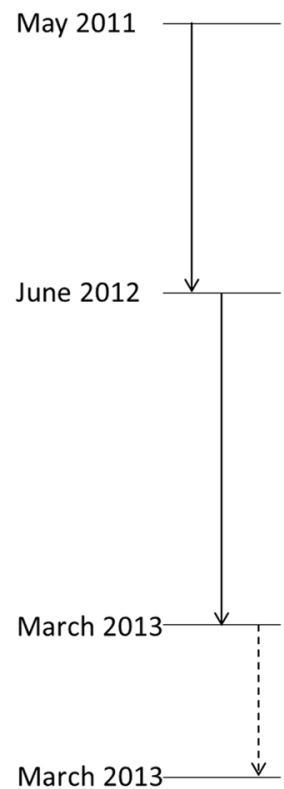

\section{Mitigation}

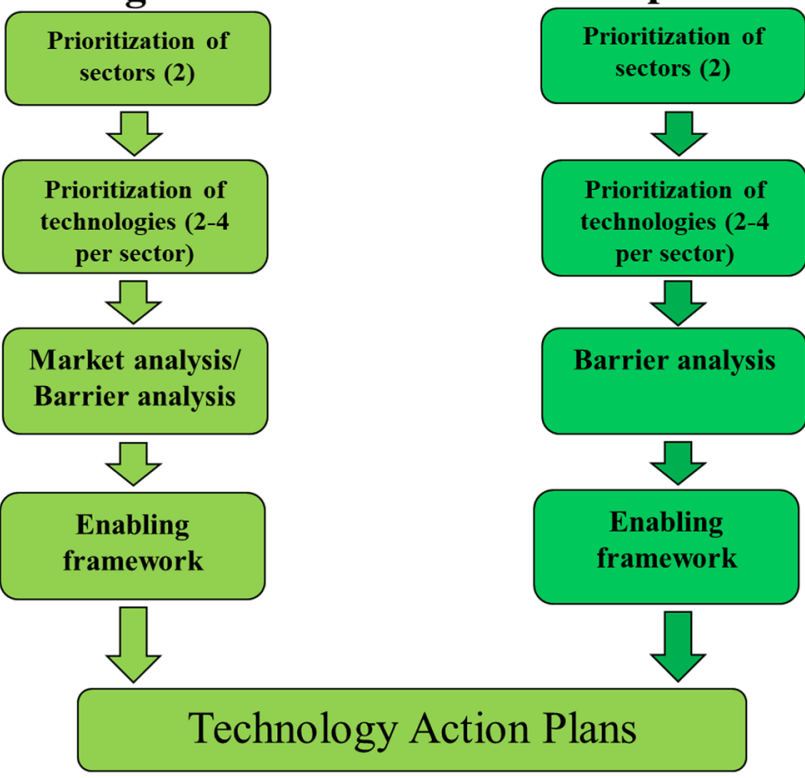

SEYCHELLES

Start: Beginning 2015

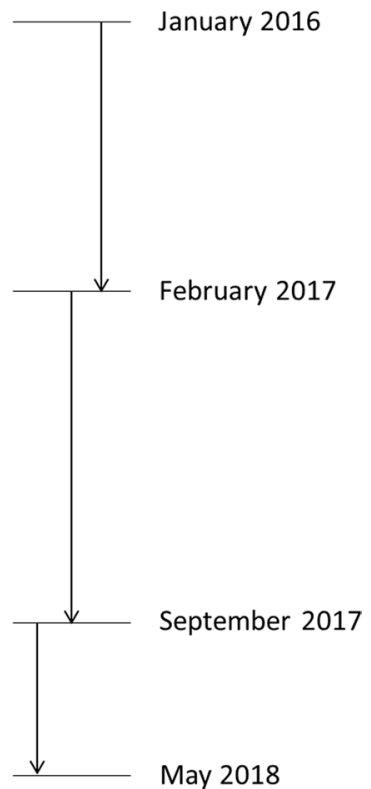

Fig. 3 Steps and time lines of the TNA process

in the entire process, and, if not managed properly, they run the risk of participation fatigue. Stakeholder fatigue can happen through the sheer number and frequency of meetings, and examples of this phenomenon are well documented in the literature (Collins et al. 2005; Gramberger et al. 2015; Leal Filho and Brandli 2016; Newton and Elliot 2016; Lemos et al. 2018). Another attendant factor is to know who and when to engage for an effective multi-stakeholder process, not just in terms of capacity to contribute toward the process of knowledge co-creation but also not to unduly load stakeholders in order to avoid fatigue (Cooke and Kothari 2001; Lemos et al. 2018). These issues are amplified in SIDS (because of relatively small population sizes) and developing countries (may have large population sizes but with low human capacities) with limited human expertise implying that a small group of local experts participate in several projects and regular administrative work simultaneously. Hence, an increased level of care is required to design a productive multi-stakeholder process.

Further, the TNA project is usually one of the smallest projects in terms of funding level (typically between USD120,000 to USD150,000) in the portfolio of projects managed by the national implementing institution, which is typically the Ministry of Environment or similar. This can result in the TNA project receiving less administrative attention that can adversely impact the effectiveness of stakeholder engagement and coordination. Also, grant-financed projects may be perceived as the repository of public institutions only; a disposition that may lead to the exclusion of non-state actors from the TNA process. Although not a particular concern for SIDS, it can be anticipated that larger country where adaptation initiatives may need to be coordinated across different geographical scales will face additional challenges of developing multi-stakeholder engagement processes that take into account different levels of climate governance (Pomeranz and Decker 2018). The TNA Step by Step guidebook (Haselip et al. 2019) provides support to countries in navigating these hurdles, and the lessons learned from Mauritius and Seychelles provide complementary insights in putting in place meaningful, inclusive stakeholder engagement processes.

(1) Identification of stakeholders: Adequate stakeholder identification and engagements has proved to be critical for conducting a successful TNA process since quality and success strongly depend on political will and co-ownership by the relevant stakeholders (UNEP 2020). The second step of the TNA process uses the market chain mapping technique to establish the value chain of prioritized technologies (Nygaard and Hansen 2015; Haselip et al. 2019). The market mapping technique is used to understand the enabling environment in which technology is implemented. In Mauritius, the use of this technique was enlarged to cover the policy space over and above the technology chains and used at the beginning of the TNA process to identify the stakeholders that either has an interest in a particular priority sector or have an influence on decision making on policy and technology choices in that sector. This is an example of how a thorough understanding at the start of the entire TNA 
process and the tools that it proposes can play a significant role in enhancing the effectiveness of technology identification, prioritization, and action planning.

This approach can be useful in identifying stakeholders at different geographical scales and levels of governance. The approach used in Mauritius and Seychelles, therefore, responded well to the need for strengthening the involvement of the private sector and local government in the TNA process (UNEP, 2020). Also, the use of the mapping technique can be adjusted at each step of the TNA process to identify the most appropriate stakeholders to engage with based on their interest, knowledge, commitment, and decision power (UNEP 2020).

(2) Mixed stakeholder engagement approaches to avoid participation fatigue: Three stakeholder engagement approaches were used in order to maintain a good balance between achieving project objectives and minimizing stakeholder fatigue. Plenary sessions in the form of training workshops (between 3 to 4 ) were used for the capacity development of all project stakeholders on the TNA process, tools and methodologies. Technical working group (TWG) sessions were used for identifying and prioritizing sectorspecific technologies, carrying out barriers analyses and formulating TAPs. For example, the TNA project in Mauritius used a total of 30 TWG meetings that lasted between 2 to $3 \mathrm{~h}$ each. This total was spread across four technical working groups (institutional organization discussed below), implying that each TWG was involved in an average of 7 to 8 work sessions. In order to minimize the TWG sessions that are the main cause of fatigue, all sectoral and technology baseline analyses, including information gathering and data collection, were carried out using bilateral meetings involving key informants. This approach also avoided the unnecessary use of multi-stakeholder meetings (Cooke and Kothari 2001; Lemos et al. 2018). Bilateral meetings (exceeding the number of TWG meetings) also proved to be an efficient means of overcoming power differences during TWG meetings (Hemmati 2002) to obtain information and data that would otherwise not be obtained in large group meetings; to deal with political sensitivities around policy orientations and choice of technologies for prioritization. Given the small geographical area of island states, national consultants recruited to carry out the TNA project had prior strong relationships with the key stakeholders in their respective sectors, making the use of bilateral meetings a highly productive stakeholder engagement approach. The mixed stakeholder engagement approaches suited well the context of island states that are constrained in human capacities due to their small population size.

(3) Private sector engagement: As mentioned in the methodology section, one of the recommendations of the independent evaluation of phase 1 and 2 of the global TNA project was to ensure adequate participation of the private sector. Since Mauritius and Seychelles had participated in phase 1 and phase 2 of the global TNA project, respectively, it could be anticipated that both countries would suffer from this shortcoming. Nevertheless, there are several examples of private sector participation in the TNA processes, arguably due to the high prominence of the private sector in the socio-economic development of the two SIDS. With the exception of the water sector in Seychelles, there was participation of private stakeholders in all prioritized adaptation sectors as shown in Table 3. Regarding water adaptation technologies in Mauritius, private sector participation took place predominantly in step 2 of the TNA related to barriers and benefit-cost analyses.

\section{Using existing institutional structures to increase ownership}

In supporting a productive multi-stakeholder process, the case of Seychelles (Fig. 4) is used to illustrate how several
Table 3 Private stakeholder participation in TNAs

\begin{tabular}{ll}
\hline Mauritius (Republic of Mauritius & Agriculture \\
2013) & - Mauritius Chamber of Agriculture \\
& - Mauritius Sugar Industry Research Institute \\
& - Mauritius Sugar Planters Association \\
& - Farmers Service Corporation \\
& - Small Planters Welfare Fund \\
& Water \\
& - Sales managers (selected)/supermarkets and retail outlets \\
& - Scene-Ries Consult Ltd \\
& Coastal zones \\
& - Association of Hotels and Restaurants in Mauritius (AHRIM) \\
Coastal zones \\
Seychelles (Government of Seychelles \\
- 2 civil/coastal engineers \\
- Independent consultants working on ecosystem-based adaptation \\
\hline
\end{tabular}


Fig. 4 Institutional structure of Seychelles TNA project

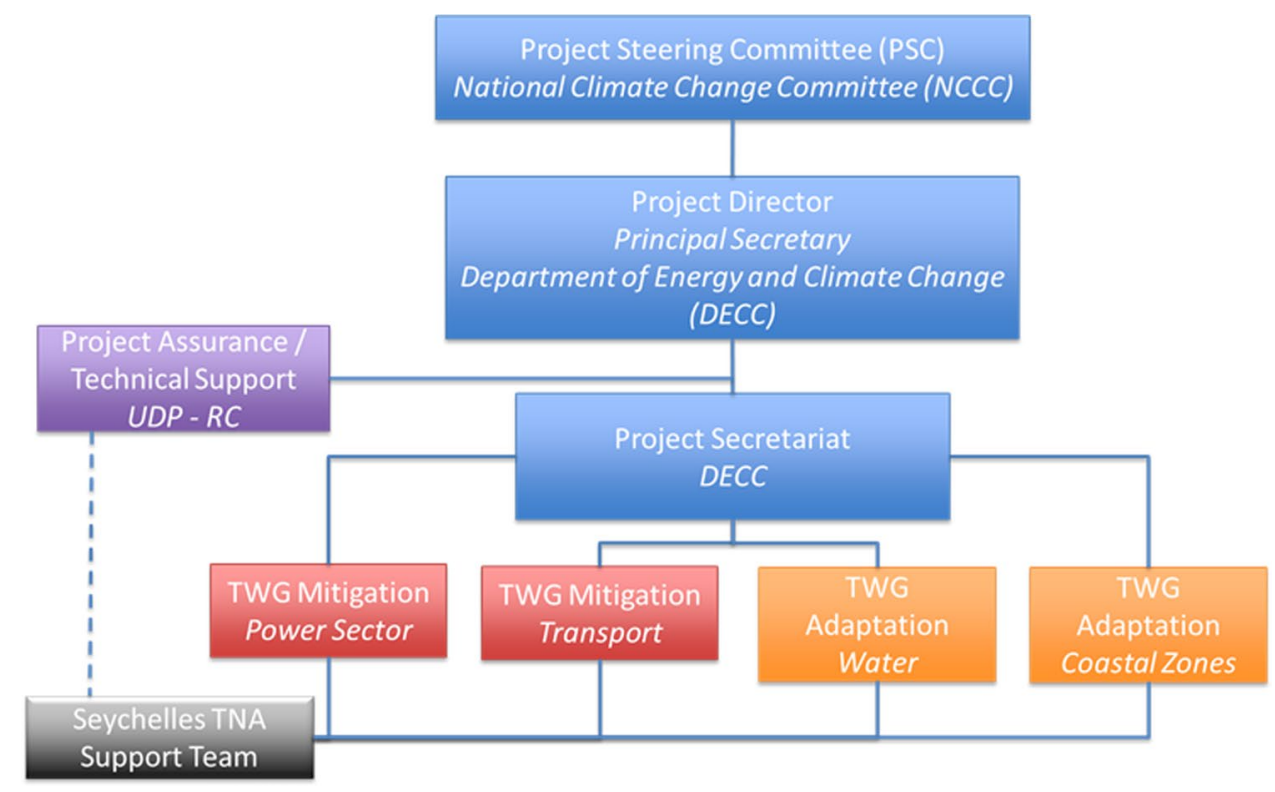

issues were addressed to ensure productive stakeholder coordination. It is pointed out that a similar structure was used in the Mauritius TNA, and the institutional governance is now formalized in the newly proclaimed Climate Change Act 2020 (Republic of Mauritius 2020). Foremost, an existing structure was used to oversee TNA project implementation and to coordinate all stakeholders. This is an important consideration for avoiding duplication and undue participation fatigue of stakeholders as previously discussed. The National Climate Change Committee (NCCC) provides political support to all climate-related initiatives in Seychelles was used. This approach had the dual benefit of avoiding the multiplicity of institutional structures and providing better synergies between different climate change projects. The NCCC is chaired by the national climate change focal point, which is also the UNFCCC National Designated Entity (NDE). A review of the phase 2 TNA project has reported that incorporating the NDE in a leading position in the governance structure appeared to be strongly beneficial (UNEP, 2020). This person is also the Principal Secretary of the Ministry of Energy, Environment and Climate Change, and heads the Department of Energy and Climate Change. This department acted as the secretariat for the TNA project.

One institutional challenge that can emerge from this structure is a conflict between coordination and policy mandate. While the NDE is the focal point for climate change and may be responsible for coordinating stakeholders on all matters related to climate change, it does not have the political mandate over each of the priority adaptation sectors. This is a critical issue in the TNA process wherein priority adaptation sectors over which the implementing or coordinating institution does not have a mandate are covered. This translates directly into a matter of ownership of the results of TNAs. If the entire TNA process were coordinated and implemented by the climate change focal point (here, the Ministry of Environment), there could be a high likelihood that the results would not be appropriated by line ministries (e.g., water, agriculture, coastal zones, and tourism) that will be called upon to implement the TAPs.

The institutional structure shown in Fig. 4 effectively addressed the potential conflict between stakeholder coordination and appropriation of the results of TNAs. While the role of the climate change focal point is undeniable as far as stakeholder coordination is concerned, the implementation of the three steps of the TNA was carried out in technical working groups (TWG) chaired by the national institution that had political mandate over the priority adaptation sectors. For instance, the power and water sector TWGs were chaired by representatives from the Public Utilities Corporation (PUC) that has the mandate for policy decision making in the energy industries and water sector in Seychelles. So, all technical work under the TNA was carried out under the aegis of the public institution that had the political mandate for priority sectors in TWGs, with coordination of stakeholders facilitated by the climate change focal point. The TWGs were composed of institutional stakeholders or individuals who had been identified using the approach discussed above. At step 2 of the TNA process, the composition of a TWG included technical specialists on the prioritized technologies who might not have participated in step 1 . This institutional organization ensured that the TNA process and TAPs, albeit coordinated by the Ministry of Environment or equivalent, was owned by line ministries. Further, a high-level executive from each priority sector was a member of the project steering committee-i.e., the NCCC in 
the case of Seychelles. All these ensured that the TAPs were promptly approved by the Cabinet of Ministers once the TAPs had been validated. The ownership of the TNA results by line ministries contributed to their integration into sectoral policies and strategies and use in leveraging international climate finance as discussed below.

\section{Replication of the technology needs assessment methodology}

As mentioned earlier, one problem inherent to the TNA project is its relatively small size, implying its limited sectoral scope. There are two issues that arise from this constraint, namely: (i) an assessment of technology needs cannot be carried out for all national priority sectors; and (ii) the cascading effect of the limited application of the TNA methodology is reduced institutional outreach and limited human and institutional capacity strengthening. As discussed above, private sector stakeholders, although being a key stakeholder group in socioeconomic development, tend to have less exposure to the TNA process and methodology. Two examples are provided on how the TNA process and methodology can be scaled up, with the second related directly to private sector applications.

(1) UNFCCC related projects: In Mauritius, the use of the TNA process, methodologies and tools were scaled up in the UNFCCC-financed Third National Communication to carry out mitigation scenario analyses to 2050 and to develop the chapter on technology development and transfer (Republic of Mauritius 2016). The same process and methodologies are currently being used to implement the GEF-financed project entitled "Nationally Appropriate Mitigation Actions (NAMAs) for Low Carbon Island Development Strategy for the Republic of Mauritius."

(2) Private sector applications: In a process of continued institutional strengthening and capacity development in Mauritius, the TNA process and methodologies have been scaled up to cover broader sustainability issues. In particular, the process and tools have been applied in the area of corporate sustainability reporting to identify material sustainability topics for private companies. In this case, value chain mapping and multi-criteria analysis, coupled with a multi-stakeholder engagement process, have been employed to support corporate sustainability reporting using the Global Reporting Initiative Standards among private sector companies in Mauritius since 2014 (Omnicane Ltd 2016). The TNA prioritization and action planning tools have been used to prioritize sustainability topics. Value chain mapping has been used to identify stakeholders and to better understand and create the enabling environment in which corporate sustainability takes place.

\section{Adopting a learning-by-doing capacity development approach}

A recent evaluation of the TNA project identified an issue that still remained to be solved relating to the imbalance in know-how and knowledge between the different stakeholders (UNEP, 2020). Another issue that is inherent to the TNA project is its total reliance on consultants, which undermines the institutional sustainability of the TNA process after the project lifetime. The TNA project provides capacity building to national consultants and TNA project coordinators, but the outreach remains limited to ensure sustainability beyond the project lifetime. A learning-by-doing capacity development approach, built around three blocks, has been applied in Mauritius and Seychelles to circumvent these issues. Also, the delivery of training to all stakeholders and the co-development of open source tools proved to be effective means for motivating stakeholders to contribute toward project success over the relatively long project lifetimes. Creating conditions wherein stakeholders can directly benefit from projects is known to mitigate stakeholder fatigue (Leal Filho and Brandli 2016; Ockwell and Byrne 2016; Newton and Elliot 2016).

(1) Understanding the entire process before starting: The experience of Mauritius and Seychelles shows that a thorough understanding of the entire TNA process, especially in terms of how its three steps are interlinked, is critical in developing high quality, bankable TAPs. It is important to understand how process design and tools could be optimized to feedback or feedforward across the different steps. While the TNA project is organized and implemented in sequential steps, all national consultants and TWG members received upfront training on the linkages between the three steps, as well as on how to optimize the use of tools that are used at the different steps. One example of the use of value chain mapping (TNA tool at step 2) for stakeholder identification at step 1 was discussed earlier. Another example is on linking the design of the multi-criteria analysis (MCA) tool that is used in step 1 for prioritizing technologies with the economic and financial analyses that need to be carried out in step 2. In the two countries, MCA included sustainable development (financial, economic, social and environmental) criteria and a balanced combination of quantitative and qualitative indicators (Deenapanray and Ramma 2015). The quantitative indicators were directly linked with the benefit-cost analyses used in step 2 to justify investments in adaptation technologies.

(2) Training on monetary and non-monetary decisionmaking tools: The TNA process adopts MCA (non-monetary technique) for technology prioritization (step 1) and benefit-cost analysis (monetary technique) in the analysis of barriers and enabling environment (step 2). All project stakeholders, including national consultants, received training on 
monetary (simply payback time, net present value, internal rate of return, cost-benefit analysis, and cost-effectiveness analysis), and non-monetary (multi-criteria analysis) decision-making methods. This was done prior to embarking on step 1 of the TNA process, and it was a sequel to the training on understanding the entire TNA process.

(3) Co-development of open source tools: Capacity development of the skills of TWG members was used as motivation for their ongoing participation in the TNA project. TWG members provided their valuable time, and the project reciprocated by providing hands on capacity building. Consequently, the TNA projects in Mauritius and Seychelles developed open source tools to carry out MCA and financial and economic analysis, and the tools, at least in Mauritius, were co-developed by consultants and members of TWG. While members provide data for computation, they were trained on the computation methods. The process of learning and discovery, coupled with the multi-stakeholder approaches discussed earlier ensured high levels of stakeholder buy-in and minimized stakeholder participation fatigue. All tools developed by the TNA project were made available to all stakeholders as open-source tools.

\section{Effectiveness of the technology needs assessment process}

Following the framing approach given in Fig. 2, the effectiveness of the TNA processes in Mauritius and Seychelles are discussed from two perspectives, namely: (i) bankability of the results of TNAs; and (2) integration of the TNA results in national policies and strategies.

\section{Bankability of the technology needs assessments and technology action plans}

As discussed by Oh (2019), one of the issues contested by developed countries related to the effectiveness of the TNA project to convert TAPs and project ideas into bankable projects. Although there is no normative framework yet to assess the quality of TAPs, and that no attempts have been made to-date to evaluate the quality of TAPs that have been developed under the post-Poznan global TNA project, a qualitative measure is used here in terms of the ability of a country to use TAPs to develop bankable projects that can be used to attract additional climate finance. Table 3 lists the TAPs that have contributed directly to attracting international climate finance in Mauritius and Seychelles. Successful mitigation TAPs are also listed since they also reflect the quality of the TNA process. The formulation of mitigation TAPs, which adopts the same but parallel process with different stakeholders, is equally influenced as adaptation TAPs by the enabling factors already discussed. The larger number of examples from Mauritius is probably related to the time lag between concluding a TNA and using its results to formulate project proposals. It is also related to the conjecture in terms of opportunities for tapping into international climate finance. Both factors worked in the favor of Mauritius that completed its TNA several years before Seychelles.

\section{Supporting sectoral policies, strategies, and the United Nations Framework Convention on Climate Change-related initiatives}

It is recognized that a TNA should not be conducted in isolation but rather integrated with other similar ongoing processes in order to support national sustainable development and, not least, the implementation of countries' NDCs. This is another criterion on which to judge the success of the TNA project (Oh 2019). A few selected examples are provided to showcase how the results of the TNA project have shaped national policies, strategies and UNFCCC-related initiatives. A specific case of private sector application in Mauritius is also provided to illustrate the scaling up of the TNA process and tools beyond climate change to touch on other sustainability issues.

(1) National policies and strategies: In Seychelles, the results of the TNA-TAP for the coastal zones were wholly integrated in the Seychelles Coastal Management Plan 2019-024 (World Bank and MEECC 2019). An exercise is currently on track to support the Government of Seychelles to mobilize financial resources to implement the Plan. In this respect, the World Bank has launched an expression of interest for a firm to do coastal dynamic studies at all of the sites around Mahé, Praslin, and La Digue identified in the Coastal Zone Risk mapping and Monitoring TAP (Table 4).

(2) UNFCCC-related initiatives: The results of TNAs have directly contributed to the development of the NDC in Mauritius (Charlery and Traerup 2019). In Seychelles, the integration process was somewhat reversed since the TNA project followed the NDC formulation process. This has provided an opportunity to identify and prioritize adaptation technologies related to the adaptation contributions of Seychelles. There is a distinct advantage of carrying out TNAs prior to NDC formulation or update since adaptation TAPs can then be used directly to inform adaptation contributions. In this scenario (e.g., Mauritius), adaptation contributions can be justified based on a robust TNA process producing sectoral adaptation plans that are fully budgeted. However, it must be pointed out that while the timeline for updating NDCs is known and is under the control of a country, a country cannot choose the timing for carrying out a TNA because this is a process dictated by GEF funding windows. Seychelles represents an example of country wherein funding opportunities for the TNA arose after the formulation of the NDC. Since Seychelles' first NDC did not contain 
Table 4 List of TAPs that have attracted climate finance: Mauritius and Seychelles

TAPs Transformation into bankable projects

Energy efficient boilers in industry (mitigation and Mauritius) TAP integrated in the GEF6-financed project "Realising Energy Savings and Climate Benefits of Implementing Mandatory Energy Audits in Coordination with HCFC Phase-out and HFC-avoidance" (Grant-US\$4,532,164; Co-financing-US\$17,870,000) (https://www.thegef.org/project/realising-energy-savin gs-and-climate-benefits-implementing-mandatory-energy-auditing. Accessed 22 Jan 2021)

Integrated pest management (adaptation and Mauritius)

Micro-irrigation (adaptation and Mauritius)

Low carbon (private) car fleet (mitigation and Seychelles)

Waste-to-energy TAP and Biomass for power generation TAP (mitigation and Seychelles)
European Union-funded Global Climate Change Alliance (GCCA+) project "Rearing of predators and parasites to support the implementation of Integrated Pest Management" (Grant-US\$300,000) under the broader umbrella programme to support climate-smart agriculture in Mauritius (http://www. govmu.org/English/News/Pages/Beneficiaries-receive-grant-under-EUGCCA+-Flagship-initiative-to-support-Climate-Smart-Agriculture.aspx. Accessed 22 Jan 2021)

International Atomic Energy Authority (IAEA) Regional African project "Promotion of small-scale gravity-fed irrigation system to improve agricultural productivity" (Grant-US\$15,000 to support 25 farmers initially) (https://www. iaea.org/newscenter/news/more-bountiful-crops-every-drop-using-drip-irrig ation-mauritius. Accessed 22 Jan 2021)

Elements of TAP related to electric vehicles integrated with the national project of Seychelles under the UNEP-GEF Global E-Mobility Programme that is currently under development (https://www.thegef.org/project/global-programmesupport-countries-shift-electric-mobility. Accessed 22 Jan 2021)

Elements of the TAPs are covered by the CTCN-financed technical assistance to Seychelles under the project entitled "Formulating a national electricity code" (https://www.ctc-n.org/news/ctcn-seychelles-formulating-national-electricitygrid-code. Accessed 22 Jan 2021) detailed climate adaptation plans and budgets, the TNA process supported further development of such budgeted plans. The case of Mauritius also shows that once the capacity for carrying out TNA is acquired, it can be scaled up in other climate adaptation-related initiatives for subsequently feeding into the national process to update the NDC.

\section{Technology action plans and the Green Climate Fund investment criteria}

Since the GCF is currently the largest multilateral fund available to implement climate change adaptation in SIDS, it would be useful to improve the bankability of TAPs by adequately responding to the GCF Investment Criteria. The degree of alignment of the TAPs with the GCF Investment Criteria is summarized in Table 5, and the ensuing discussions focus on insights to improve TAPs to respond better to the GCF Investment Criteria. Since the "needs of the recipient" and "country ownership" are factors that are built into the TNA process (UNFCCC 2008; 2010; 2012), they are not discussed further.

The "paradigm shift" criterion is currently not explicitly addressed in TNAs-TAPs including those of Mauritius and Seychelles. However, it is argued that most of the elements for addressing this criterion are available to develop a theory of change to reduce climate vulnerability and/or increase resilience at scale through the transfer, absorption, and diffusion of a basket of prioritized adaptation technologies. This will require two things in particular: (1) a programmatic approach has to be used to develop long term targets for prioritized adaptation technologies. This requirement will effectively also address the "impact potential" criterion of the GCF. In the case of Mauritius, TAPs covered a period of at least 10 years to ensure transfer and diffusion of adaptation technologies at scale (Deenapanray and Ramma 2015); and (2) the theory of change will need to be developed for the ensemble of prioritized adaptation technologies-that is for the ensemble of all TAPs rather than for individual TAPs. This will require an assessment of the combined effects of a bundle of technologies on reducing vulnerabilities or increasing resilience rather than focusing on prioritized technologies in isolation from each other as is currently done in TNAs-TAPs. The bundling of technologies to adapt to climate change will arguably contribute to higher positive impacts of technology transfer (Fleischer et al. 2011) thereby further improving on the "impact potential" criterion.

As discussed earlier, there is an imperative for integrating the first two steps of the TNA process rather than viewing them as two mutually exclusive sequential steps. This implies a connection between the "sustainable development potential" and "efficiency and effectiveness" criteria. Hence, the appropriate choice of criteria and indicators in MCA 
Table 5 Degree of alignment of TAPs with GCF Investment Criteria

\begin{tabular}{ll}
\hline GCF investment criteria & Degree of alignment in TAPs \\
\hline Impact potential & $\begin{array}{c}\text { For each prioritized technology, financial and economic analyses are carried out in step } 2 \text { of the TNA pro- } \\
\text { cess. These analyses are premised on a penetration target for the technology to be transferred. Hence, there } \\
\text { is an opportunity to set ambitious technology penetration targets for ensuring high impact and scaling up } \\
\text { technology transfer } \\
\text { Not addressed in the TNA process and TAPs } \\
\text { The prioritization of technologies in step 1 of the TNA process uses multi-criteria analysis (MCA) as previ- } \\
\text { ously discussed. The MCA process offers the opportunity to identify sustainable development criteria and } \\
\text { country-specific indicators to carry out the prioritization of climate technologies } \\
\text { This criterion is aligned with the overarching objective of the TNA project to assess the climate technology } \\
\text { needs of the recipient country (UNFCCC 2008; 2010; 2012) } \\
\text { The TNA is defined as a country-driven process (Boldt et al. 2012), and all three steps are carried out under } \\
\text { the aegis of mandated national institutions } \\
\text { In step } 2 \text { of the TNA process, countries have to make the economic/financial case for investing in prioritized } \\
\text { adaptation technologies. This allows for the efficiency and effectiveness criterion to be duly addressed in } \\
\text { the TNA. In the previous discussion, it was shown that economic and financial analyses can be improved } \\
\text { through developing a sound MCA framework for prioritizing technologies. The use of objective indica- } \\
\text { tors during the MCA can be directly linked with financial and economic analyses to respond to the GCF } \\
\text { requirements of efficiency and effectiveness }\end{array}$ \\
\end{tabular}

for prioritizing adaptation technologies can be used to carry out better financial and economic analyses for justifying the "efficiency and effectiveness" criterion. For instance, the criteria and indicators that have been used for prioritizing adaptation technologies in Mauritius combine subjective and objective indicators across several sustainable development criteria for delivering the highest sustainable development dividends (Deenapanray and Ramma 2015). The criteria and indicators were chosen by stakeholders to respond to national developmental needs. Hence, the logic underpinning the prioritization of technologies is that the topmost prioritized technologies should effectively deliver the highest sustainable development benefits. The objective indicators allowed for economic analyses to be carried out for a 10-year target level of each prioritized adaptation technology (using a programmatic approach) to make the economic case for technology transfer. Robust economic and financial analysis is considered to be the strength of TAPs developed by Mauritius and Seychelles.

\section{Conclusions}

Although several countries have completed their TNA projects financed by the Global Environment Facility, there is a conspicuous lack of lessons shared drawn from in-country experiences for completing successful TNAs. Mauritius and Seychelles are SIDS that have completed their TNAs, and they stand as good candidates for sharing lessons learned from the perspectives of efficiency and effectiveness. Drawing from the experiences of Mauritius and Seychelles, several propositions have been made to enhance the efficiency of stakeholder engagements and coordination, as follows: (1) The TNA process is quite intensive on stakeholder engagement and care must be exercised to design a process that minimizes stakeholder fatigue; (2) An institutional architecture is needed for allowing effective coordination of the TNA project by the national climate change focal point (typically the Ministry of Environment) while ensuring the appropriation of the TNA process and results by other line ministries (e.g., water, agriculture, coastal zones, or tourism) in order to enhance country ownership; and (3) Examples of the human capacity building using a learning-by-doing methodology and institutional strengthening through the replication of the TNA methodology beyond the TNA project are provided to showcase their contributions toward motivating stakeholders, including the private sector.

While acknowledging that there is currently no normative approach for assessing the relative success of TNAs, a case has been made for assessing the effectiveness of TNAs from two perspectives, namely: (1) the bankability of TAPs and (2) the integration of the TNA results in national climate policies and strategies. Examples have been provided on how the TNA process, methodologies and tools have been scaled up beyond the TNA project to support the formulation of sectoral adaptation strategies and to support other UNFCCC-related initiatives such as the formulation of nationally determined contributions and national communications. It has been shown that the TNA results in Mauritius have been used successfully to access international climate finance.

Finally, a critical analysis has been provided for increasing the bankability of TAPs by ensuring that they address even more closely the investment criteria of the Green Climate Fund. Drawing from the lessons learned in Mauritius and Seychelles, 
it has been shown that several GCF investment criteria are already well addressed by the existing TNA-TAP methodology. A proposal has been made on how the "paradigm shift" criterion that is currently not accounted for in the TNA-TAP methodology can be covered in TAPs using a programmatic approach while simultaneously enhancing the prospects for impact at scale. Better alignment with the GEF investment criteria will surely increase the quality and bankability of TAPs.

Supplementary Information The online version contains supplementary material available at https://doi.org/10.1007/s10113-021-01859-y.

\section{References}

Biagini B, Kuhl L, Gallagher KS, Ortiz C (2014) Technology transfer for adaptation. Nat Clim Change 4:828-834. https://doi.org/10. 1038/NCLIMATE2305

Boldt J, Nygaard I, Hansen UE, Trærup S (2012) Overcoming barriers to the transfer and diffusion of climate technologies. UNEP Ris $\varnothing$ Centre, Roskilde

Bozeman B (2000) Technology transfer and public policy: a review of research and theory. Res Policy 29:627-655. https://doi.org/10. 1016/S0048-7333(99)00093-1

Brooks H (1995) Marshalling technology for development. National Academies Press, Washington DC, pp 83-96

Charlery L, Trærup SLM (2019) The nexus between nationally determined contributions and technology needs assessments: a global analysis. Clim Policy 19:189-205. https://doi.org/10.1080/14693062.2018.1479957

Collins E, Kearins K, Roper J (2005) The risks of relying on stakeholder engagement for the achievement of sustainability. Electronic Journal of Radical Organization Theory 9:81-101

Cooke B, Kothari U (2001) Participation: the new tyranny? Zed Books, London

Deenapanray P, Ramma I (2015) Adaptations to Climate Change and Climate Variability in the Agriculture Sector in Mauritius: Lessons from a Technology Needs Assessment. In Ganpat W, Isaac W-A (eds) Impacts of Climate Change on Food Security in Small Island Developing States, IGI Global, Hershey, PA https://doi.org/ 10.4018/978-1-4666-6501-9

De Commarmond A, Payet R (2010) Small island developing states: incubators of innovative adaptation and sustainable technologies? In: Michel D, Pandya A (eds) Coastal zones and climate change. Stimson Center, Washington DC, pp 51-68

Eichberger J, Guerdjikova A (2012) Technology adoption and adaptation to climate change - a case-based approach. Clim Change Econ 3:1-41. https://doi.org/10.1142/S2010007812500078

Fida E (2011) Experiences in conducting technology needs assessment (TNAs) for adaptation from non Annex I countries under the "top up” phase. In: Christiansen L, Olhoff A, Trærup S (eds) Technologies for adaptation: perspectives and practical experiences, UNEP Ris $\varnothing$ Centre, Roskilde 45-58

Fleischer A, Mendelsohn R, Dinar A (2011) Bundling agricultural technologies to adapt to climate change. Technol Forecast Soc Change 78:982-990. https://doi.org/10.1016/j.techfore.2011.02.008

Fowler A, Biekart K (2017) Multi-stakeholder initiatives for sustainable development goals: the importance of interlocutors. Public Adm Dev 37:81-93. https://doi.org/10.1002/pad.1795

Government of Seychelles (2018) Seychelles technology action plan - adaptation. Ministry of Environment, Energy and Climate Change, Seychelles
Gramberger M, Zellmer K, Kok K, Metzger MJ (2015) Stakeholder integrated research (STIR): a new approach tested in climate change adaptation research. Clim Change 128:201-214. https:// doi.org/10.1007/s10584-014-1225-x

Haselip J, Narkevičiūtė R, Rogat J, Trærup S (2019) TNA step by step: a guidebook for countries conducting a technology needs assessment and action plan. UNEP DTU Partnership, Copenhagen

Hemmati M (2002) Multi-stakeholder processes for governance and sustainability: beyond deadlock and conflict. Routledge, London

IPCC (2014) Summary for policymakers. In: Climate Change 2014: impacts, adaptation, and vulnerability. Part A: Global and Sectoral Aspects. Contribution of Working Group II to the Fifth Assessment Report of the Intergovernmental Panel on Climate Change [Field, C.B., V.R. Barros, D.J. Dokken, K.J. Mach, M.D. Mastrandrea, T.E. Bilir, M. Chatterjee, K.L. Ebi, Y.O. Estrada, R.C. Genova, B. Girma, E.S. Kissel, A.N. Levy, S. MacCracken, P.R. Mastrandrea, and L.L. White (eds.)]. Cambridge University Press, Cambridge, United Kingdom and New York, NY, USA 1-32.

Kuhl L (2020) Technology transfer and adoption for smallholder climate change adaptation: opportunities and challenges. Clim Dev 12:353-368. https://doi.org/10.1080/17565529.2019.1630349

Leal Filho W, Brandli L (2016) Engaging stakeholders for sustainable development. In: Leal Filho W, Brandli (eds.), Engaging Stakeholders in Education for Sustainable Development at University Level, World Sustainability Series https://doi.org/10.1007/9783-319-26734-0_21

Le Manceau LJ, Trærup S, Dierks S, Hecl V ( 2020) TNA regional technology brief - Africa. UNEP DTU Partnership, Copenhagen and UNFCCC, Bonn. https://tech-action.unepdtu.org/publicatio ns/regional-technology-brief-africa/.

Lemos MC, Arnott JC, Ardoin NM, Baja K, Bednarek AT (2018) To co-produce or not to co-produce. Nat Sustain 1:722-724. https:// doi.org/10.1038/s41893-018-0191-0

Newton A, Elliott M (2016) A typology of stakeholders and guidelines for engagement in transdisciplinary, participatory processes. Front Mar Sci 3:230. https://doi.org/10.3389/fmars.2016.00230

Nygaard I, Hansen UE (2015) Overcoming barriers to the transfer and diffusion of climate technologies, 2nd edn. UNEP DTU Partnership, Copenhagen

Ockwell D, Byrne R (2016) Improving technology transfer through national systems of innovation: climate relevant innovation-system builders (CRIBs). Clim Policy 16:836-854. https://doi.org/ $10.1080 / 14693062.2015 .1052958$

Oh C (2019) Political economy of international policy on the transfer of environmentally sound technologies in global climate change regime. New Political Econ 24:22-36. https://doi.org/10.1080/ 13563467.2017.1417361

Omnicane Ltd (2016) Defining the report content for Omnicane Ltd using the global reporting initiative G4 sustainability reporting guidelines: the materiality matrix and stakeholder engagement. Omnicane Ltd, Port Louis

Pomeranz EF, Decker DJ (2018) Designing regional-level stakeholder engagement processes: striving for good governance while meeting the challenges of scale. J Environ Pol Plan 20:403-418. https://doi.org/10.1080/1523908X.2017.1417119

Republic of Mauritius (2013) Technology action plan and project idea report for adaptation: agriculture, water and coastal zone. Ministry of Environment and Sustainable Development, Port Louis

Republic of Mauritius (2020) the climate change act 2020, government gazette of Mauritius No. 145 of 28 November 2020.

Trærup SLM, Christiansen L (2015) Adaptation technologies as drivers of social development. In: Inderberg TH, Eriksen S, O'Brien K, Sygna L (eds) Climate change adaptation and development: Transforming paradigms and practices. Routledge, London, pp 98-116 
UNEP (2020) Terminal evaluation of the UNEP/GEF project "Technology Needs Assessment Phase II (2014-2018)”. Evaluation Office of UN Environment, Nairobi

UNFCCC (1992) United Nations framework convention on climate change. https://unfccc.int/files/essential_background/background_ publications_htmlpdf/application/pdf/conveng.pdf.

UNFCCC (2001) Report of the conference of the parties on the seventh session, Held at Marrakesh from 29 October to 10 November 2001 (FCCC/CP/2001/13/Add.1). http://unfecc.int/resource/docs/cop7/ 13a01.pdf.

UNFCCC (2008) Report of the conference of the parties on its fourteenth session, held in Poznan from 1 to 12 December 2008. https://unfccc.int/resource/docs/2008/cop14/eng/07a01.pdf.

UNFCCC (2010) Report of the conference of the parties on its sixteenth session, held in Cancun from 29 November to 10 December 2010. http://unfccc.int/resource/docs/2010/cop16/eng/07a01.pdf.

UNFCCC (2012) Report of the conference of the parties on its eighteenth session, held in Doha from 26 November to 8 December 2012. https://unfccc.int/resource/docs/2012/cop18/eng/08a02.pdf.

UNFCCC (2015) Report of the conference of the parties on its twentyfirst session, held in Paris from 30 November to 13 December 2015. https://unfccc.int/resource/docs/2015/cop21/eng/10a01.pdf.
UNFCCC (2018) Report of the conference of the parties on its twenty fourth session, held in Katowice from 2 to 15 December 2018. https://unfccc.int/sites/default/files/resource/10a2e.pdf.

UNSD (1992) United Nations conference on environment \& development. https://sustainabledevelopment.un.org/content/documents/ Agenda21.pdf.

World Bank and ministry of environment, energy and climate change of Seychelles (2019) Seychelles Coastal Management Plan: 20192024. World Bank, Washington DC

Zilberman D, Zhao J, Heiman A (2012) Adoption versus adaptation, with emphasis on climate change. Annu Rev Resour Econ 4:2753. https://doi.org/10.1146/annurev-resource-083110-115954

Publisher's Note Springer Nature remains neutral with regard to jurisdictional claims in published maps and institutional affiliations. 